\title{
Promoting Education Sustainable Development Through English Writing Skills Performance Improvement - Case Study on Students' Perception in Undergraduate Writing Course
}

\author{
S T Sela, M R Putri \\ Faculty of Humanities, Universitas Bina Nusantara, Jakarta, Indonesia \\ ssela@binus.edu
}

\begin{abstract}
Academic writing is introduced to higher education students since the first year at BINUS University. A course named English for Academic Writing focuses on the development and improvement of academic writing skills in the English language of students in Global Class. The respondents are the students of Computer Science and Information System. Data was collected through an onlinesurvey filled by the students, and interview with the lecturer. The collected data will be analyzed qualitatively and quantitatively. This paper discusses the perception of students on the improvement of academic writing skills applied in writing an abstract, introduction, literature review, methodology,andreferences. The students mentioned skills such as citing, paraphrasing, referencing, quoting, problem/topic statement writing, finding/result writing were hard to be learned. The students practiced those skills manually and using the feature in Microsoft Words. The result will provide data and information about the improvement made, so the teaching-learning activities applied could become suggestions or feedbacks for the respective class and parallel classes. Therefore, this papersupports the building of students' capacity in English academic writing skills for sustainable development in education.
\end{abstract}

Keywords: Academic writing, English language, Writing skills

\section{INTRODUCTION}

The students of higher education are required to provide academic writing to graduate from the university. Iftanti [1]. wrote that writing is important as it is applied to some daily activities. Global Class in Bina Nusantara University is a type of class that all courses delivered in English so that the academic writing or the thesis will be written in English as well. There is an English course named English for Academic Writing that focused on learning and development of academic writing skills for undergraduate students. The course outputs are the academic papers written by the students. The students learned about writing the sections in academic writing: abstract, introduction, literature review, methodology, findings $\&$ discussions, and references. In writing those sections, the students learned to apply APA styles and demonstrated citing, quoting, referencing, paraphrasing and plagiarism. The students were divided into some groups. Each group had a mini project that they had to write 
an academic paper based on the research they conducted. During the process of writing, the students could come to discuss any difficulties with the lecturer. The students are encouraged to benefit all the resources available to support the research and the writing.

This paper focused on the perception of the students of Global Class Bina Nusantara University for the improvement of academic writing skills in supporting the sustainable development for quality education. This paper will discuss: 1) The academic writing skills they have learned, 2) The challenges in accomplishing the writing, 3) The other skills learned, 4) The improvement made, and 5) Learned skills for sustainable development. The findings of the paper will be the suggestion and feedback to the respective class and other parallel classes. Knowing and understanding the way of thinking and how the students perceived the improvement made, will be feedback to develop teaching-learning strategies that support quality education for sustainable development.

\section{LITERATURE REVIEW}

This paper discussed the perception of the respondents, academic writing skills, the improvement made and the skills supported the sustainable development for quality education.

\subsection{Perception}

There were many variables that influenced the perceptions explained by Tagoe [2]. The perception was a result of process subjectively. It depended on the value of the person, the experiences and knowledge, Masek [3] wrote in the paper.

\subsection{Academic Writing Skills}

Pawliczek [4] wrote that creative writing could improve the ways of thinking. While the skills of advanced writing in the higher education were the important elements of academic performance, Kellogg [5] explained.

\subsection{Skills for Sustainable Development in Education}

Laurie, [6] wrote on the research that education for sustainable development pedagogies was often issue-based. It stimulated the critical thinking through discussions. Leicht [7]. mentioned the competencies that support the sustainable development for quality education. The competencies were systems thinking competency, anticipatory competency, critical thinking competency, collaboration competency, and some other competencies. These competencies could be developed while learning academic writing.

\section{METHODOLOGY}

This paper applied the mix method, the quantitative and qualitative methods. A quantitative method was used to describe the number of respondents while the qualitative described the improvement made based on the perception of the students. 


\subsection{Respondent}

This paper is to describe the improvement of academic writing skills based on the perception of the students. So there were two types of respondents. The first respondents were the students and the second was the lecturer of the respective classes.

\subsubsection{The Students}

There were 50 students of the two classes of English for Academic Writing course in the university as the first respondent.

\subsubsection{The Lecturer}

The second respondent was the respective lecturer of the classes. The lecturer gave the information and data to clarify and validate the data gathered from the students.

\subsection{Instrument}

The data was collected through an online questionnaire and interview. Google Form was used to collect the data from the students. The link of Google Form was sent to the students. The emails were sent to the lecturer and an interview was conducted to gather data and information from the lecturer.

\subsection{Data Analysis}

Analysis of data was displayed in numbers. The number was then described qualitatively to answer the research questions.

\section{RESULT AND DISCUSSION}

There are four research questions discussed in this paper: 1) The academic writing skills they have learned, 2) The challenges in accomplishing the writing, 3) The other skills learned and developed, 4) The improvement made, and 5) Improved skills for sustainable development.

\subsection{The academic writing skills they have learned}

The respondents mentioned some academic writing skills. So, there was more than one skill learned for each respondent. Out of 50 respondents, Table 1 showed that 20 respondents learned Referencing/APA Styles, 24 respondents learned about citation, 4 respondents learned about quotation, 10 respondents learned about paraphrase, 7 respondents learned about plagiarism, and 28 respondents learned about writing. Each respondent may write more than 1 skill.

Table 1. Academic Writing Skills Learned by Students.

\begin{tabular}{cc}
\hline Skills & Number of Respondents \\
\hline Referencing/APA Styles & 20 \\
Citation & 24 \\
Quotation & 4 \\
Paraphrase & 10 \\
Plagiarism & 7 \\
Writing & 28 \\
\hline
\end{tabular}




\subsection{The Challenges in Accomplishing the Writing}

Challenges faced by students in writing were as follows, 32 respondents answered that the challenges were to write citation, paraphrasing, referencing and quoting, 8 respondents answered that writing the problem or topic statement was the challenge, 10 students answered that writing the result was the difficult part.

Table 2. Challenges in accomplishing the writing.

\begin{tabular}{cc}
\hline Challenges & Number of Respondents \\
\hline Writing citation, paraphrasing, referencing, quoting & 32 \\
Writing the problem/topic statement & 8 \\
Writing the result/findings & 10 \\
\hline
\end{tabular}

\subsection{The Other Skills Learned and Developed}

In the process of conducting research and writing the academic paper, the students learned other skills. Table 3 showed that 21 respondents learned about critical thinking, 22 respondents learned about collaboration, 19 respondents learned about communication, and 5 respondents learned English.

Table 3. Other skills learned by the students.

\begin{tabular}{|c|c|}
\hline Other Skills & Number of Respondents \\
\hline Critical Thinking & 21 \\
\hline Collaboration & 22 \\
\hline Communication & 19 \\
\hline English & 5 \\
\hline
\end{tabular}

\subsection{The Improvement Result}

Table 4 showed that according to 44 respondents, the academic writing skills have been improved. The other 6 respondents mentioned that the skills have been good and very good or stay fair.

Table 4. Improvement Result.

\begin{tabular}{cccccc}
\hline Respondent & $\begin{array}{c}\text { Skills } \\
\text { improved }\end{array}$ & Respondent & $\begin{array}{c}\text { Skills } \\
\text { improved }\end{array}$ & Respondent & $\begin{array}{c}\text { Skills } \\
\text { improved }\end{array}$ \\
\hline 1 & No & 18 & No & 36 & Yes \\
2 & Yes & 19 & Yes & 37 & No \\
3 & Yes & 20 & Yes & 38 & Yes \\
4 & Yes & 21 & Yes & 39 & Yes \\
5 & Yes & 22 & Yes & 40 & No \\
6 & Yes & 23 & Yes & 41 & Yes \\
\hline
\end{tabular}




\begin{tabular}{cccccc}
\hline 7 & Yes & 24 & Yes & 42 & Yes \\
8 & Yes & 25 & Yes & 43 & Yes \\
9 & Yes & 26 & No & 44 & Yes \\
10 & Yes & 27 & Yes & 45 & Yes \\
11 & Yes & 28 & No & 46 & Yes \\
12 & Yes & 29 & Yes & 47 & Yes \\
13 & Yes & 30 & Yes & 48 & Yes \\
14 & Yes & 31 & Yes & 49 & Yes \\
15 & Yes & 32 & Yes & 50 & Yes \\
16 & Yes & 33 & Yes & & \\
17 & No & 34 & Yes & & \\
\hline
\end{tabular}

\subsection{Learned Skills for Sustainable Development}

Table 5 showed that according to the respondents, critical thinking and collaboration skills learned in the process of learning English for academic writing. These skills support the sustainable development.

Table 5. Learned Skills for sustainable development.

\begin{tabular}{|c|c|}
\hline Skills & Number of Respondents \\
\hline Critical Thinking & 21 \\
\hline Collaboration & 22 \\
\hline
\end{tabular}

\section{CONCLUSION}

The improvement of the academic writing skills showed above based on the perception of the respondents. The lecturer mentioned that most students got at least score 80 for the course. This showed that the improvement had been made. There were academic writing skills learned related to referencing/APA Styles, citation, quotation, paraphrase, plagiarism. There were challenges: writing references, quotation, paraphrase, citation; writing problem or topic statement; writing result or findings, faced in the process. There were also other skills learned such as critical thinking, collaboration, and communication, beside English skills itself.

The lecturer applied collaborative learning where the students had to conduct research and write the paper in a group. The online quizzes and consultation session had been given during the process. The skills for sustainable development such as critical thinking and collaboration also learned during the process of the learning.

\section{REFERENCES}

[1] E. Iftanti, "Improving Students' Writing Skills Through Writing Journal Articles," J. Bhs. Ling. Sci., vol. 8, no. 1, Jun. 2016.

[2] M. Tagoe, "Students' perceptions on incorporating e-learning into teaching and learning at the University of Ghana," Int. J. Educ. Dev. using Inf. Commun. Technol., vol. 8, no. 1, pp. 91-103, 2012.

[3] A. Masek and N. A. Ngah Nasaruddin, "Students' Perception and Readiness on 
School-Based Assessment," Mediterr. J. Soc. Sci., vol. 7, no. 6, Nov. 2016.

[4] Joanna Pawliczak, "Creative Writing as a Best Way to Improve Writing Skills of Students," Sino-US English Teach., vol. 12, no. 5, May 2015.

[5] R. T. Kellogg and B. A. Raulerson, "Improving the writing skills of college students," Psychon. Bull. Rev., vol. 14, no. 2, pp. 237-242, Apr. 2007.

[6] R. Laurie, Y. Nonoyama-Tarumi, R. Mckeown, and C. Hopkins, "Contributions of Education for Sustainable Development (ESD) to Quality Education: A Synthesis of Research,” J. Educ. Sustain. Dev., vol. 10, no. 2, pp. 226-242, Sep. 2016.

[7] A. Leicht, H. Julia, and B. W. Jung, Issues and trends in Education for Sustainable Development. Paris: United Nations Educational, Scientific and Cultural Organization, 2018. 